\title{
A Serverless Advanced Metering Infrastructure Based on Fog-Edge Computing for a Smart Grid: A Comparison Study for Energy Sector in Iraq
}

\author{
Ammar Albayati 1,*(D), Nor Fadzilah Abdullah 1,*(D), Asma Abu-Samah 1,*(D), \\ Ammar Hussein Mutlag ${ }^{2}(\mathbb{D})$ and Rosdiadee Nordin ${ }^{1}$ (D) \\ 1 Faculty of Engineering \& Built Environment, Universiti Kebangsaan Malaysia, Bangi 43600, Malaysia; \\ adee@ukm.edu.my \\ 2 Faculty of Electrical Engineering, Middle Technical University, Baghdad 10001, Iraq; \\ ammar_alqiesy@yahoo.com \\ * Correspondence: p98736@siswa.ukm.edu.my (A.A.); fadzilah.abdullah@ukm.edu.my (N.F.A.); \\ asma@ukm.edu.my (A.A.-S.)
}

Received: 21 September 2020; Accepted: 15 October 2020; Published: 19 October 2020

\begin{abstract}
The development of the smart grid (SG) has the potential to bring significant improvements to the energy generation, transmission, and distribution sectors. Hence, adequate handling of fluctuating energy demands is required. This can only be achieved by implementing the concept of transactive energy. Transactive energy aims to optimize energy production, transmission, and distribution combined with next-generation hardware and software, making it a challenge for implementation at a national level, and to ensure the effective collaboration of energy exchange between consumers and producers, a serverless architecture based on functionality can make significant contributions to the smart grids advanced metering infrastructure (SG-AMI). In this paper, a scalable serverless SG-AMI architecture is proposed based on fog-edge computing, virtualization consideration, and Function as a service (FaaS) as a services model to increase the operational flexibility, increase the system performance, and reduce the total cost of ownership. The design was benchmarked against the Iraqi Ministry of Electricity (MOELC) proposed designs for the smart grid, and it was evaluated based on the MOELC traditional computing-design, and a related cloud computing-based design. The results show that our proposed design offers an improvement of $20 \%$ to $65 \%$ performance on network traffic load, latency, and time to respond, with a reduction of $50 \%$ to $67 \%$ on the total cost of ownership, lower power and cooling consumption compared to the SG design proposed by MOELC. From this paper, it can be observed that a robust roadmap for SG-AMI architecture can effectively contribute towards increasing the scalability and interoperability, automation, and standardization of the energy sector.
\end{abstract}

Keywords: smart grid; advanced metering infrastructure; fog computing; serverless; Function as a Services (FaaS)

\section{Introduction}

In the past few years, the use of technologies associated with distributed energy management and renewable energy has increased considerably. In this account, the smart grid (SG) is found to be a prominent solution to improve the efficiency and transparency of energy transfer between producers and consumers. This new approach follows the principles of transactive energy (TE), a systematic process of controlling and managing energy flow while maintaining a dynamic balance across electrical systems to market-based standards and economic values [1]. TE can solve the energy supply and demand problems between consumers and producers by smartly optimizing energy flow and directing 
it to where it is needed. TE and SG's concepts are based on the Industrial Revolution (IR) 4.0 to optimize energy distribution, transmission, and generation, combined with next-generation hardware and software [2].

To enhance transactive energy, the SG-AMI (Advanced Metering Infrastructure) concept has been getting major attention and is considered as the next generation of power systems to increase the overall reliability and efficiency of power transmission $[3,4]$. Smart grids contain transmission and power generation utilities combined with sensing devices, meters, information gateways, and appliances that work in real-time. AMI with bi-directional capability (read and write to smart meters) was developed to enhance the unidirectional and static Automatic Meter Reading (AMR). It consists of a combination of networks and systems responsible for analyzing and collecting data from smart meters and handles power and services-related applications based on them. AMI also facilitates the flow of data in a bi-directional way within three network-zone systems, i.e., Wide Area Network (WAN), Neighborhood Area Network (NAN), and Home Area Network (HAN). Each of these has its own existing and potential applications, as shown in Figure 1 [5]. AMI is composed of two main components, namely, the Head End System (HES) and Meter Data Management System (MDMS). HES is a combination of hardware and software that performs data validation on meter data that it receives from smart meters [6,7]. MDMS validates the data management and data storage received from the smart metering system [8]. AMI reduces the cost of meter reading and creates an automated bill for customers based on readings that it obtains from the meters [9]. The sensing devices in SG observe and measure the system's performance while looking for any glitches. In case of any failure detection, sensing devices forward a message to the control center.

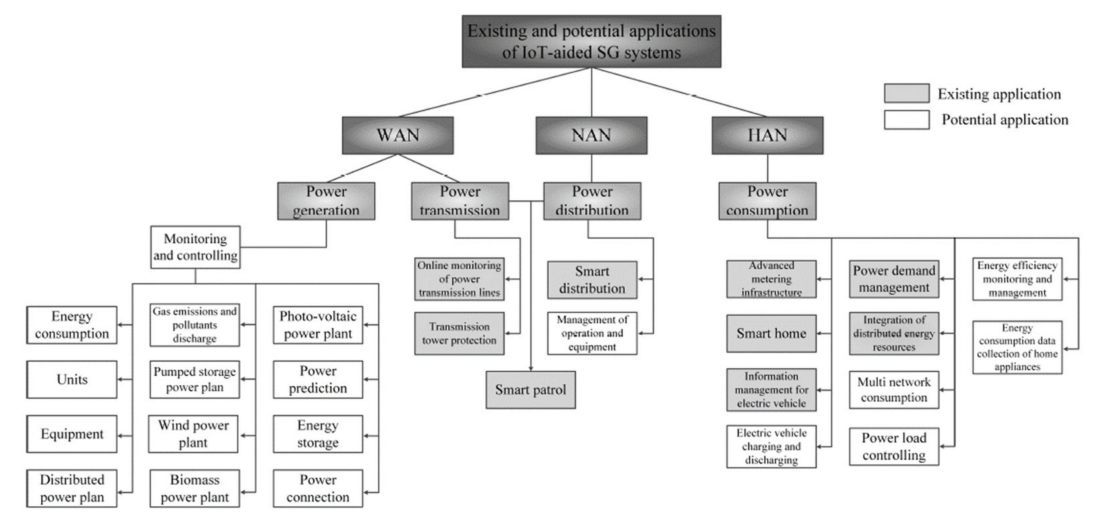

Figure 1. Existing and potential applications of IoT-aided smart grid (SG) systems are classified into Wide Area Network (WAN), Neighborhood Area Network (NAN), and Home Area Network (HAN) [5].

Meanwhile, the industrial sectors' rapid development leads to increasing demand for energy and a time-dependent demand fluctuation [10]. As a result, the effectiveness of the SG-AMI faces various technical challenges. These include cybersecurity, storage concerns, performance, scalability, and data management $[5,11]$. Data management complexity remains the most crucial problem due to the huge number of smart meters and controllers that retrieve data to enhance the operator's capabilities [5], risking the smart grid's slow down [12]. Furthermore, economic challenges include the expensive initial and running costs of SG-AMI. The optimization of architecture design for SG with real-time AMI can drastically enhance the data management issue and improve the operation's cost [5]. The real-time interaction with utility companies and consumers is made possible via communication channels to offer many benefits, including self-healing mechanisms in an emergency, auto-metering, active monitoring, security, reliability, and efficient energy management [13].

Diverse smart grid computing architectures were introduced in the last few years that include but are not limited to cloud computing, fog computing, edge computing, traditional computing, and hybrid computing [14]. Each of these designs can be adapted to computing service models like on-premises, infrastructure as a Service (IaaS), Platform as a Service (PaaS), Back-end as a Service 
(BaaS), and Software as a Service (SaaS) [15]. Another new concept introduced recently in the smart grid design is the serverless Infrastructure, Function as a Service (FaaS) [16]. The serverless concept does not mean having any servers in the infrastructure, instead, it means that services as a function are offered to deliver full back-end infrastructure resources to consumers. The design helps energy companies develop their energy business model without thinking about the underlying infrastructure. As a result, the total costs of ownership (TCO) required to deploy SG-AMI application can be significantly reduced by relying only on the pay-as-you-go service per needed function. Figure 2 shows the differences between the computing service model structures. Gray boxes represent the end-users management while white boxes show the service providers. FaaS is evolving as a modern and convincing model for SG-AMI application delivery, primarily attributed to the rapid transition of corporate technology frameworks to microservices [16]. FaaS will assist developers and companies to concentrate on business logic as an alternative from focusing on infrastructure or managing the software environment itself, so they can progress their production and transform their visions to real services.

\begin{tabular}{|c|c|c|c|c|c|}
\hline On Premises & $\begin{array}{c}\text { Infrastructure } \\
\text { as a Service }\end{array}$ & $\begin{array}{c}\text { Platform } \\
\text { as a Service }\end{array}$ & $\begin{array}{c}\text { Backend } \\
\text { as a Service }\end{array}$ & $\begin{array}{c}\text { Function } \\
\text { as a Service }\end{array}$ & $\begin{array}{c}\text { Software } \\
\text { as a Service }\end{array}$ \\
\hline Business Logic & Business Logic & Business Logic & Business Logic & Business Logic & Business Logic \\
\hline Application & Application & Application & Application & Application & Application \\
\hline Data & Data & Data & Data & Data \\
\hline Runtime & Runtime & Runtime & Runtime & Runtime & Runtime \\
\hline OS & OS & OS & OS & OS \\
\hline Virtualization
\end{tabular}

Figure 2. Comparison of different Computing Service models structure [17].

This paper aims to propose a scalable serverless architecture design for the SG-AMI, with Iraq as a case study. The study suggests much more dependence on the FaaS and BaaS services model on top of virtualization technology to reduce the total cost of ownership and improve operational performance. The rest of this paper is structured as follows. Section 2 elaborates on the technologies relevant to the SG architecture. Section 3 specifies the case study for SG-AMI deployment by Iraqi MOELC, while Section 4 explains the proposed SG-AMI architecture that considers Fog-Edge computing and virtualization to improve the scalability, system performance, total cost of ownership, and operational flexibility. Section 5 presents a scenario with improved system configuration to evaluate the performance and response management that shows the proposed architecture improves the latency and response time compared to the architecture used by MOELC. Finally, Section 6 concludes the paper.

\section{Related Works}

Due to the increased demands to improve energy consumption, the economy has shifted towards developing intelligent networks to optimize energy utilization [18]. The use of intelligent energy networks can optimize energy flow, the way it is produced, transmitted, and distributed, while reducing the cost of energy. To support such networks, different computing infrastructure can be used to solve the implementation hurdles related to the ineffective use of multiple smart devices and huge data handling. The four computing technologies are traditional, cloud, fog, and edge computing. First, the most basic traditional computing (TC) which by far is the least preferred method despite being simpler to implement compared to other computing methods. On top of limitations such as low performance and scalability, TC follows a centralized computing architecture that can limit the smart grid's potential, thus increasing the TCO.

Second, the revolutionary cloud-based architecture which is widely used to cater to high demand responses in a large-scale network deployment [19]. Cloud computing (CC) is the backbone of smart services and products as it performs the communication process and provides network access to 
many SG computing resources while responding in a real-time manner to run multiple applications. The realization of the concept via the smart grid is based on handling a vast amount of data, and this data management is achieved by using big data technologies [20]. It has the potential to optimize the supply of resources to consumers while retaining a low investment and cost of operation. According to [21], CC can effectively increase the efficiency, flexibility, security, and scalability. Although CC supports high performance based on centralized computational platforms, it still has restrictions such as traffic complexities, high latency and response time, security, and privacy issues [22,23].

Third, fog computing (FC) is an additional layer between the smart grid physical network and the cloud that fills the processing power gap between these two entities. The problem of massive traffic generation by CC can be resolved using fog computing [24]. Data that do not necessarily need to be sent to the cloud is processed in the fog layer devices, thus reducing the response time [14]. Several studies $[25,26]$ have proposed that the latency and time to response issue can be resolved using fog computing that provides most of the computational resources within the end user's proximity. However, these studies lack an analysis of expected cost-effectiveness for the proposed architecture compared to other conventional infrastructure. FC can reduce processing costs by refining the data and providing local processing support to smart grids [27]. This aspect can reduce the risk of latency affecting the overall performance, while increasing the amount of data processed by smart grids and decreasing the use of extra resources, ultimately reducing the overall cost.

Finally, edge computing (EC) that enables advanced systems to perform complex computations, processing delay-sensitive and bandwidth-hungry applications near the data or end-user devices. It extends CC capabilities, bringing services close to the network's edge [14-28]. Like FC, EC complements CC by significantly reducing the latency, improving the virtualization support, allowing seamless connectivity, reducing energy consumption, and improving energy management. [29] to improve the overall total cost of ownership. Although FC effectively manages local customer's requests while providing network and computation services between users and cloud computing applications, edge computing can observe smart grid subscribers' distribution and consumption patterns. However, note that if enough computational power is not supplied to edge computing, latency can be slower than fog computing [14]. Moreover, edge computing is limited to performing computing activities at the network's edge. Compared to cloud computing, edge computing handles load distribution and agility, which can play an effective role, specifically by monitoring the smart grid's electricity distribution.

Smart computing, from CC to EC, is also beneficial to promote optimal utilization and reduce construction and operating costs while increasing scalability and flexibility. In an energy sector, the smart computing infrastructure is compatible and can be paired with virtualization technology to improve performance by flexibly creating and distributing virtual resources [30]. Implementation and relation of new components and testing applications concerning smart grids can be conducted virtually to avoid expensive and risky operations. Previous works from Chen, Liu, and Ha [31] and Worighi et al. [32] suggested that SG virtualization enhances the utilization of resources and simplifies data center management. The studies further proclaim that because real power grids cannot be used for validation and testing, virtualization in smart grids can provide accurate testing results similar to the real systems. India and China have been undergoing a significant transformation in adopting information technology in smart grids despite challenges such as establishment and transformation cost. To counter these issues, India has opted for virtualization technology to manage its hardware and data related to smart grids [33]. Smart grid virtualization provides a dynamic pricing model in real-time and energy management to reduce load at peak times. Thus, the issue of establishing a secure and reliable communication network that has the potential to support multiple applications in AMI and Distribution Automation (DA) can be resolved using virtualization technology integrated on smart grids [34]. A further summary of previous works on SG computing infrastructure and virtualization technology is organized in Table 1. 
Table 1. Summary of the recent works on SG computing infrastructure.

\begin{tabular}{|c|c|c|c|c|}
\hline Ref. And Title & $\begin{array}{l}\text { Target Computing } \\
\text { Infrastructure }\end{array}$ & Aim & Main Services Model & Results/Issues \\
\hline Proposed architecture & $\begin{array}{l}\text { Fog-Edge computing with } \\
\text { virtualization technology } \\
\text { consideration }\end{array}$ & $\begin{array}{l}\text { A serverless SG-AMI } \\
\text { infrastructure to enhance the } \\
\text { energy sector in a developing } \\
\text { country }\end{array}$ & FaaS, SaaS, and BaaS & $\begin{array}{l}\text { A comprehensive design and } \\
\text { realistic case study, along with a } \\
\text { comparison to other conventional } \\
\text { infrastructure. It is complemented } \\
\text { by cost-effectiveness analysis. }\end{array}$ \\
\hline $\begin{array}{l}\text { [16] "Serverless computing for } \\
\text { cloud-based power grid } \\
\text { emergency generation } \\
\text { dispatch" }\end{array}$ & $\begin{array}{l}\text { Cloud computing with } \\
\text { virtualization technology } \\
\text { consideration }\end{array}$ & $\begin{array}{l}\text { A cloud-centric serverless SG } \\
\text { architecture to ensure the } \\
\text { operational continuity } \\
\text { regardless of local } \\
\text { infrastructure's availability and } \\
\text { accessibility. }\end{array}$ & FaaS & $\begin{array}{l}\text { The design did not consider the } \\
\text { high cost of relying entirely on } \\
\text { cloud computing and no } \\
\text { comparison between the proposed } \\
\text { design to any similar design. }\end{array}$ \\
\hline $\begin{array}{l}\text { [19] "A Cloud-Fog-Based Smart } \\
\text { Grid Model for Efficient } \\
\text { Resource Utilization" }\end{array}$ & Cloud and Fog computing & $\begin{array}{c}\text { A model for resource } \\
\text { management and response time. }\end{array}$ & SaaS & $\begin{array}{l}\text { A good proposal in terms of } \\
\text { efficiency, but the research did not } \\
\text { discuss the cost of data exchange } \\
\text { expected for big data when relying } \\
\text { on cloud computing. }\end{array}$ \\
\hline $\begin{array}{l}\text { [21] "Cloud computing is the } \\
\text { smart grid context: an } \\
\text { application to aid fault location } \\
\text { in distribution systems } \\
\text { concerning the multiple } \\
\text { estimation problem" }\end{array}$ & $\begin{array}{l}\text { Cloud computing with } \\
\text { virtualization technology } \\
\text { consideration }\end{array}$ & $\begin{array}{l}\text { A smart grid infrastructure to } \\
\text { store and manipulate smart } \\
\text { distribution system data }\end{array}$ & IaaS & $\begin{array}{l}\text { Proposals to use open source tools } \\
\text { to develop the AMI infrastructure } \\
\text { smartly, but no total cost of } \\
\text { operating and data transfer } \\
\text { discussion }\end{array}$ \\
\hline $\begin{array}{c}\text { [23] "A cloud-based smart } \\
\text { metering infrastructure for } \\
\text { distribution grid services and } \\
\text { automation" }\end{array}$ & Cloud computing & $\begin{array}{l}\text { A flex meter infrastructure and } \\
\text { a Smart Metering } \\
\text { architecture to foster } \\
\text { general-purpose services in the } \\
\text { smart grid. }\end{array}$ & IaaS & $\begin{array}{c}\text { Suitable suggestions for } \\
\text { interoperability, future expansions, } \\
\text { and flexible deployment, however } \\
\text { no discussion on how the services } \\
\text { will be distributed, or which } \\
\text { services model should be } \\
\text { considered. }\end{array}$ \\
\hline $\begin{array}{c}\text { [25] "Fog Computing for Smart } \\
\text { Grid Systems in the 5G } \\
\text { Environment: Challenges and } \\
\text { Solutions" }\end{array}$ & Fog computing & $\begin{array}{l}\text { Proposed a Fog Computing- } \\
\text { Smart Grid architecture based } \\
\text { on 5G infrastructure that } \\
\text { reduces the end-to-end latency } \\
\text { in comparison to the } \\
\text { conventional techniques }\end{array}$ & IaaS, SaaS, and PaaS & $\begin{array}{l}\text { Lack of analysis on expected } \\
\text { cost-effectiveness for the proposed } \\
\text { architecture lack of discussion } \\
\text { related to integrated technology } \\
\text { such as virtualization. }\end{array}$ \\
\hline
\end{tabular}


Table 1. Cont

\begin{tabular}{|c|c|c|c|c|}
\hline Ref. And Title & $\begin{array}{l}\text { Target Computing } \\
\text { Infrastructure }\end{array}$ & Aim & Main Services Model & Results/Issues \\
\hline $\begin{array}{l}\text { [26] "Feasibility of Fog } \\
\text { Computing in Smart Grid } \\
\text { Architectures" }\end{array}$ & $\begin{array}{c}\text { Fog computing (From core to } \\
\text { edge) }\end{array}$ & $\begin{array}{l}\text { Discussed the feasibility of Fog } \\
\text { Computing in Smart Grid } \\
\text { architectures and proposed an } \\
\text { edge-centered Fog computing } \\
\text { model is for Smart Grids } \\
\text { infrastructures. }\end{array}$ & SaaS & $\begin{array}{l}\text { Lack of technical presentation and } \\
\text { did not compare with other } \\
\text { conventional techniques or } \\
\text { infrastructure or performance tests. }\end{array}$ \\
\hline $\begin{array}{l}\text { [27] "Deploying Fog Computing } \\
\text { in Industrial Internet of Things } \\
\text { and Industry 4.0" }\end{array}$ & Fog computing & $\begin{array}{l}\text { Discussed the deployment of } \\
\text { fog enabled smart grid for } \\
\text { Industrial Internet of Things } \\
\text { (IIoT) and Industry } 4.0\end{array}$ & Not Available & $\begin{array}{l}\text { Although this study suggested fog } \\
\text { computing as a solution to reduce } \\
\text { the cost of transporting and } \\
\text { processing data, it overlooks any } \\
\text { discussion regarding Edge } \\
\text { computing. Moreover, there is no } \\
\text { clear service model to reduce the } \\
\text { cost of transporting and processing } \\
\text { data; there are no clear service } \\
\text { models or any specific prospective } \\
\text { application. }\end{array}$ \\
\hline $\begin{array}{c}\text { [28] “Intelligent Edge } \\
\text { Computing for IoT-Based } \\
\text { Energy Management in Smart } \\
\text { Cities" }\end{array}$ & $\begin{array}{l}\text { Edge Computing with } \\
\text { virtualization technology } \\
\text { consideration }\end{array}$ & $\begin{array}{c}\text { Enable edge computing } \\
\text { architecture for smart energy } \\
\text { management }\end{array}$ & IaaS & $\begin{array}{l}\text { No discussion on the potential } \\
\text { expansion of these systems would } \\
\text { necessitate fog computing or cloud } \\
\text { computing in more comprehensive } \\
\text { systems. Lack of details on } \\
\text { performance evaluation and } \\
\text { discussion on integrated } \\
\text { technology. }\end{array}$ \\
\hline $\begin{array}{l}\text { [29] "Internet of Things Based } \\
\text { Smart Grids Supported by } \\
\text { Intelligent Edge Computing" }\end{array}$ & $\begin{array}{l}\text { Edge Computing with } \\
\text { virtualization technology } \\
\text { consideration }\end{array}$ & IoT-based smart grids & IaaS, SaaS, and PaaS & $\begin{array}{l}\text { Interesting design in terms of } \\
\text { effectiveness to keep and retain all } \\
\text { data but neglected the high cost of } \\
\text { doing such activity, as the data } \\
\text { usually should be divided into hot } \\
\text { and cold data and store in different } \\
\text { locations. }\end{array}$ \\
\hline $\begin{array}{c}\text { [30] "Virtualization } \\
\text { Management Concept for } \\
\text { Flexible and Fault-Tolerant } \\
\text { Smart Grid Service Provision" }\end{array}$ & $\begin{array}{l}\text { Mainly focus on Virtualization } \\
\text { technology in cloud computing }\end{array}$ & $\begin{array}{l}\text { Grid Function Virtualization } \\
\text { (GFV) to improve the } \\
\text { operational flexibility of smart } \\
\text { grid automation }\end{array}$ & Not Available & $\begin{array}{l}\text { No proposition of serverless } \\
\text { services and lack of analysis for any } \\
\text { potential impact on different smart } \\
\text { grid services model. }\end{array}$ \\
\hline
\end{tabular}


This study is distinguished from its previous counterpart by being a comprehensive study proposing a serverless SG-AMI architecture with edge and fog computing to overcome both sides' challenges in the cloud computing-based solution. Moreover, it introduces virtualization technology to increase system performance and flexibility, to elastically offer many types of services models such as FaaS, BaaS, and SaaS to form a more adaptable business logic design while reducing the total cost of ownership.

\section{Case Study on Iraqi Energy Distribution Sector}

In this section, two design proposals that were obtained for the SG-AMI based on the Iraq energy distribution context are presented. The proposed SG-AMI architecture designs was produced by the Iraqi Ministry of Electricity (MOELC). Information was gathered through multiple meetings, workshops, and field visits across different departments of the Iraqi MOELC departments, including the Planning Department, Operation, and Control Department. The proposed SG-AMI designs by the MOELC show the current nationwide networks with serial structure design where the ministry HQ (zone-1) connects to four major distribution government companies (zone-2), which are in Baghdad, Middle, South, and North of Iraq. Each main distribution company dominates a group of smaller branches or sub-regions (zone-3), representing the different Iraqi provinces in this zone that are geographically closer to a zone- 2 area. All distribution companies in zone-2 are linked to the ministry HQ (zone-1) using optical fiber composite overhead ground wire (OPGW) and microwave (MW) links as backup links in case of emergency or natural disaster situations. However, most sub-regions in zone-3 are either not connected or use poor WAN links to reach zone-2. Currently, the statistics of the MOELC proclaims that more than $95 \%$ of subscribers in zone 3 are using mechanical meters. However, in the design, sub-regions in zone-3 are assumed to be linked to the smart meters (SMs), and all SM are assumed to be connected using older generation GPRS cellular network or PLC (power line communication).

Consequently, both designs are based on the idea of dealing with the portions of SG in the distribution sector, i.e., AMI components such as Head End System (HES) and Meter Data Management System (MDMS). The solution proposed for distribution infrastructure should ensure cost reduction in construction, operation, and maintenance. Figures 3 and 4 illustrate the architecture of the two MOELC proposals, as found in [35], which will be the baseline document for comparison and validation with our proposed design.

\subsection{MOELC Proposal 1: HES-Only in Zone 3}

Figure 3 shows the SG-AMI architecture in Proposal 1 of the Iraqi MOELC. It shows the plans to distribute HES in all sub-regions (zone-3), with direct links to main regions using OPGW and/or MW links. These communication infrastructures are dedicated to the MOELC and are used to connect all sub and main regions to ensure high availability. This aspect further lowers the cost of data transmission while ensuring high security and stability. However, it will increase the cost of construction. MDMS will only be used on the four main regions in zone-2, and these will directly link to the main MDMS system in HQ (zone-1). MDMS in HQ is responsible for handling data processes in all zones based on traditional computing, while all other sub-regions (zone-3) are prospected to send all gathering data to be processed by MDMS in zone-2. The main advantage of this design is ensuring the independence of both hardware and software such that the data of each region are independent of each other, and each branch is not affected by any interruptions faced by other regions operating across Iraq.

However, this design's disadvantages include high latency, low scalability, and high maintenance and operation cost. Most importantly, this design is intended to be used by MOELC government-linked companies (GLCs) without considering the expected transformation of distribution to smaller private companies. The design does not foresee the integration of these infrastructure resources with other companies in the private sector. This will force private sector companies that would like to work in 
the distribution sector to build their own complete set of SG-AMI Infrastructure, to be integrated into MOELC SG-AMI. This will increase the total cost of ownership (TCO) and waste of national resources.

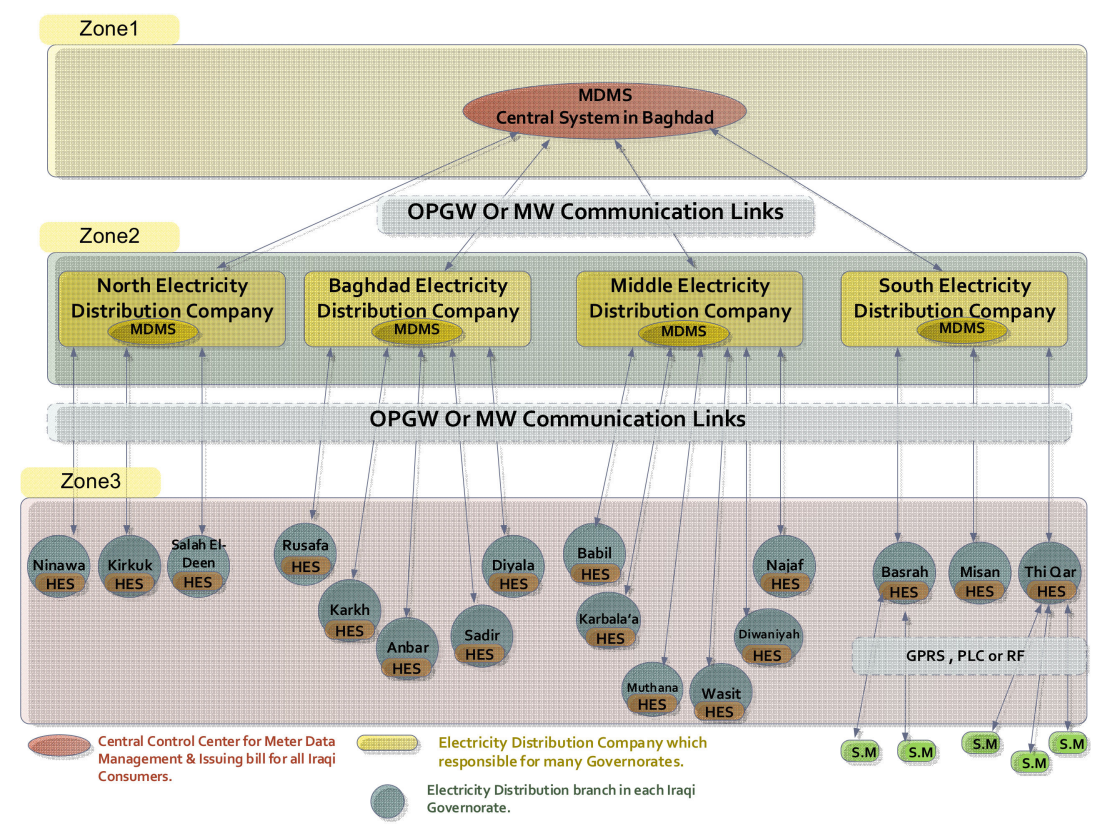

Figure 3. Proposal 1 of Iraqi Ministry of Electricity (MOELC) smart grids advanced metering infrastructure (SG-AMI) architecture.

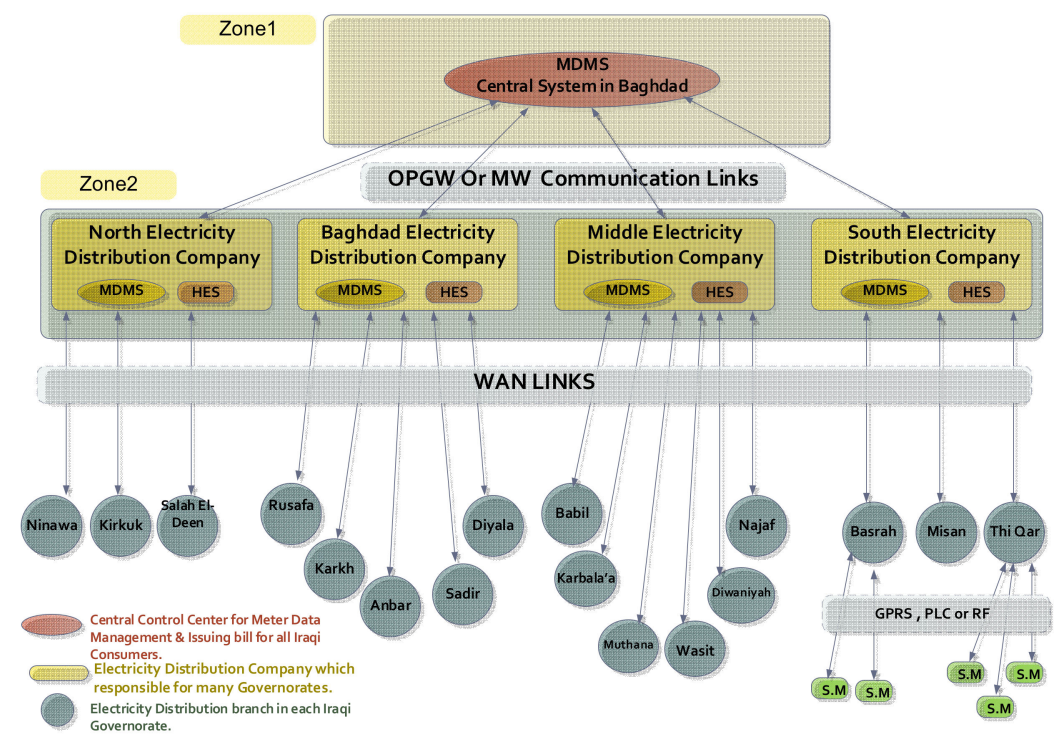

Figure 4. Proposal 2 of Iraqi MOELC SG-AMI architecture.

\subsection{Proposal 2: HES in Zone 2}

Figure 4 shows the SG architecture in Proposal 2 of the Iraqi MOELC. There are minor differences in the second proposal that reduce the total cost of ownership (TCO), according to the specialists in the MOELC. They proposed to modify the first design by installing both HES and MDMS at main regions (zone-2) while connecting the sub-region using public WAN links. This design will significantly reduce the TCO as well as maintenance and operation costs. However, the design will lose its independence and revert to centralization control, significantly increasing the latency. Besides, adopting public network communication links (WAN) for data transfer between zones and regions will greatly raise security concerns. Therefore, MOELC needs to include some advanced security technologies to enhance 
cybersecurity, such as intrusion prevention systems (IPS), advanced encryption technologies, and deep packet inspection. Like Proposal 1 of MOELC, this proposal design is also unscalable and does not consider the expected transformation of the private sector.

Table 2 summarizes the differences between the above MOELC designs Proposal 1 and 2. From the technical specification document by MOELC [35], it is clear that specialists in MOELC have depended on the legacy stack (Traditional Stack Computing) to develop the proposed designs. It was noted that the proposal by MOELC overlooked technologies such as fog computing and virtualization, which have been known to provide high efficiency, high scalability, increased reliability, and ease of future expansion.

Table 2. Comparison between MOELC Proposals 1 and 2.

\begin{tabular}{|c|c|c|}
\hline Parameters & MOELC Proposal (1) & MOELC Proposal (2) \\
\hline $\begin{array}{c}\text { Infrastructure Design } \\
\text { Virtualization Techniques }\end{array}$ & \multicolumn{2}{|c|}{$\begin{array}{c}\text { Traditional Computing } \\
\text { Not available }\end{array}$} \\
\hline $\begin{array}{c}\text { Design Zone } \\
\text { Communication link }\end{array}$ & $\begin{array}{c}\text { 3 Zone Traditional Computing } \\
\text { OPGW and/or Microwave (MW) }\end{array}$ & $\begin{array}{c}\text { 2 Zone Traditional Computing } \\
\text { OPGW andor Microwave (MW) } \\
\text { and WAN }\end{array}$ \\
\hline Scalability & \multicolumn{2}{|c|}{ Low } \\
\hline $\begin{array}{c}\text { Response Time } \\
\text { Latency }\end{array}$ & Low & $\begin{array}{c}\text { Very Low } \\
\text { Very High Latency }\end{array}$ \\
\hline $\begin{array}{c}\text { Coverage-Distribution } \\
\text { Mobility Support }\end{array}$ & $\begin{array}{c}\text { Centralized } \\
\text { No }\end{array}$ \\
\hline $\begin{array}{c}\text { Maintenance and operation cost } \\
\text { Total Cost of Ownership }\end{array}$ & $\begin{array}{c}\text { High } \\
\text { Very High }\end{array}$ & $\begin{array}{c}\text { Medium to High } \\
\text { Medium to High }\end{array}$ \\
\hline
\end{tabular}

\section{Proposed Design}

In this section, a design that considers the Iraqi MOELC future expansion, especially on transforming the private sector, is presented. The design suggests a serverless infrastructure for SG-AMI that offers services as a function (FaaS) using a virtual grid. In this design, MOELC acts as a service provider to both public and private companies in the distribution sector to use this infrastructure and offers all SG-AMI services as function without requiring the public and private companies to build their infrastructure. This will help many companies invest in energy sectors with a minimal total cost of ownership and use pay-as-you-growth models based on their respective needs and business plan perspectives. The proposed design combines the fog and edge computing for SG-AMI (FC-EC SG) architecture. It consists of three zones, where each zone has a scalable four-tier architecture based on virtualization technology and is divided into many regions and application groups or functions. The zone- 3 functions to receive the collected data from any devices or smart objects in the grids for processing and forward the request or data for the feature process in zone- 2 through API getaway. In zone 2, all active processes for specific data manipulation will be performed. The data in zone-2 are also classified as hot data (most frequently accessed data) or cold data (infrequent or low accessed data) based on historical transactions and feature extraction. Only hot data will be stored in zone-2, while all cold data will be forwarded to zone- 1 to be stored and called back only when needed. This process will ensure less data traffic to be saved and reduce the time to respond in zone 2. Figure 5 shows a high-level overview of our FC-EC SG-AMI proposed architecture design across regions, while Figure 6 shows the detailed proposed FC-EC SG-AMI by zone to illustrate the components in each region and to highlight the FaaS services block. Meanwhile, Table 3 shows the suggested distribution of different types of applications and services across SG-AMI zones and the role of services, which include 9 FaaS, $4 \mathrm{SaaS}$, and $2 \mathrm{BaaS}$ roles. Further elaboration on the design can be found below. 


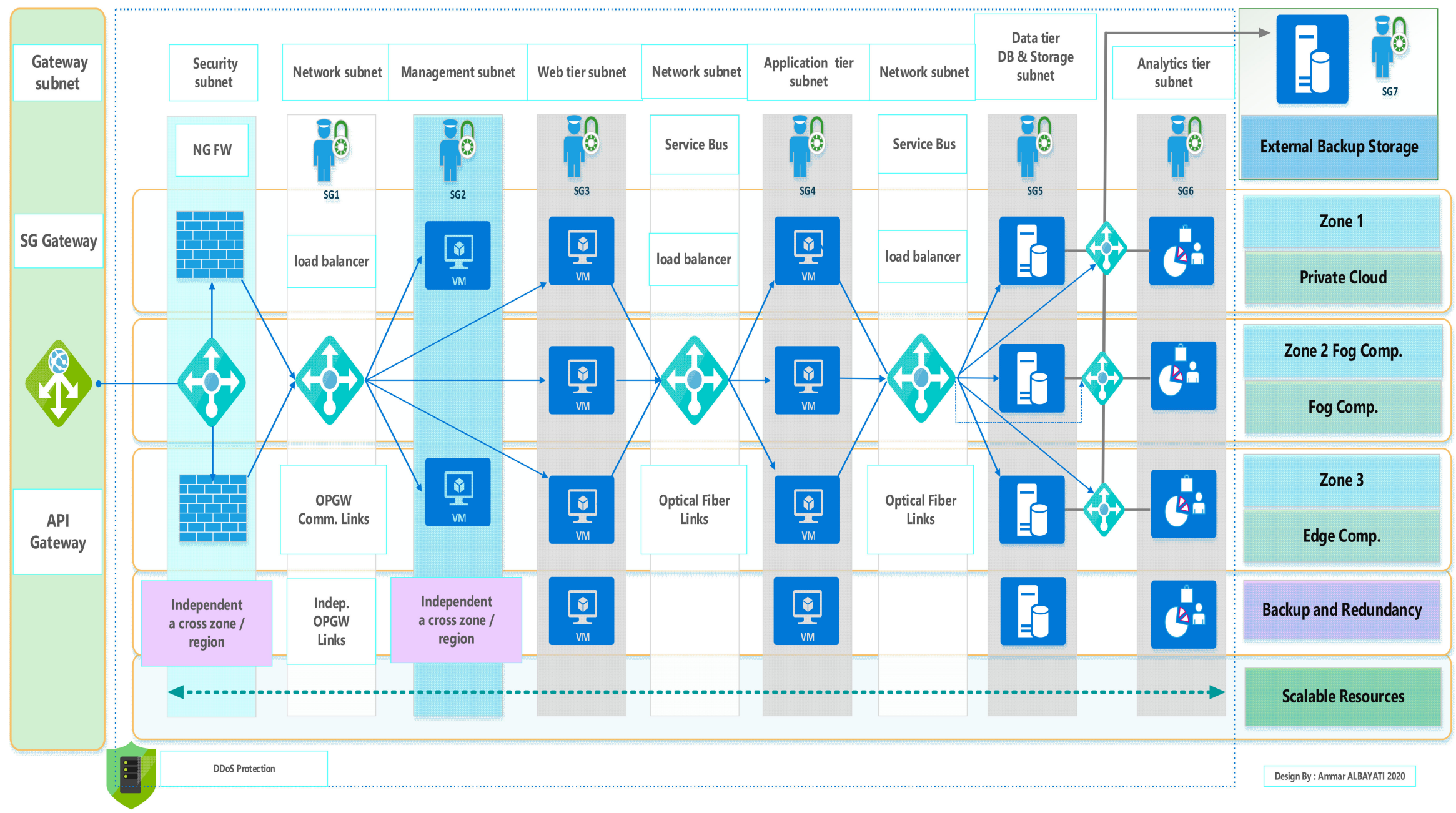

Figure 5. FC-EC SG-AMI proposed architecture design. 


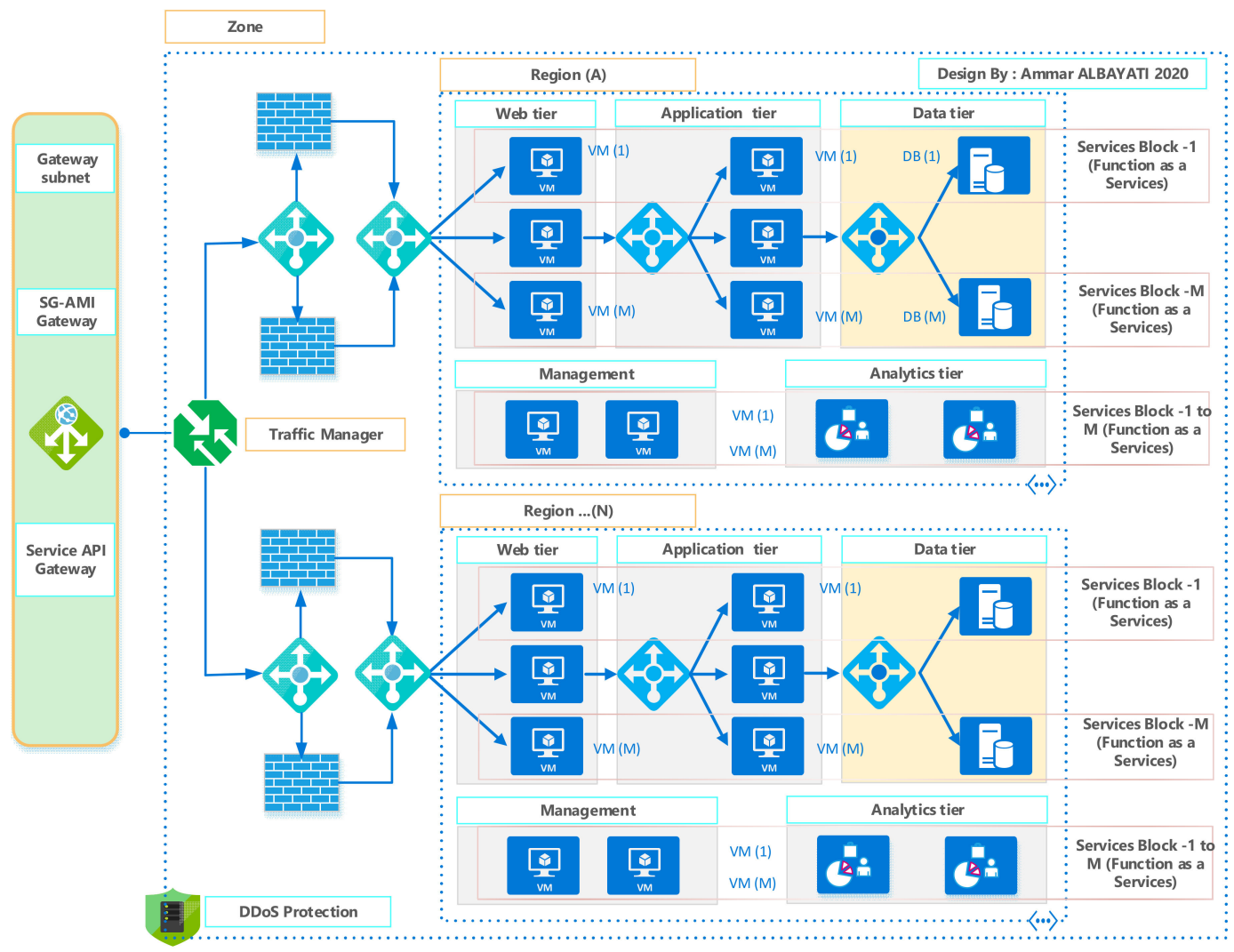

Figure 6. FC-EC SG-AMI zone, regions, and block of services.

Table 3. The distribution of SG-AMI services according to zones and the role of services.

\begin{tabular}{|c|c|c|c|c|}
\hline Applications or Services & Zone-3 & Zone-2 & Zone-1 & Role of Services \\
\hline MDMS system & $\checkmark$ & $\checkmark$ & $\checkmark$ & Function as a Service (FaaS) \\
\hline Billing Systems & $\checkmark$ & $\checkmark$ & $\checkmark$ & Software as a service (SaaS) \\
\hline Dynamic data center management & $\mathbf{x}$ & $\checkmark$ & $\checkmark$ & Function as a Service (FaaS) \\
\hline Data traffic scheduling & $\checkmark$ & $\checkmark$ & 田 & Function as a Service (FaaS) \\
\hline Dynamic demand and response & $\checkmark$ & $\checkmark$ & $\checkmark$ & Function as a Service (FaaS) \\
\hline Real-time monitoring & $\checkmark$ & $\checkmark$ & $\checkmark$ & Software as a service (SaaS) \\
\hline Analysis and Reporting & 可 & $\checkmark$ & $\checkmark$ & Software as a service (SaaS) \\
\hline Measurement and control & $\checkmark$ & $\checkmark$ & 田 & Software as a service (SaaS) \\
\hline Hot Data Storage & $\checkmark$ & $\checkmark$ & 田 & Function as a Service (FaaS) \\
\hline Cold Data Storage & 田 & 田 & $\checkmark$ & Function as a Service (FaaS) \\
\hline Security and access control & $\checkmark$ & $\checkmark$ & $\checkmark$ & Function as a Service (FaaS) \\
\hline Consumer Information System & $\checkmark$ & $\mathbf{x}$ & 田 & Function as a Service (FaaS) \\
\hline Clock Synchronization & $\checkmark$ & $\checkmark$ & $\checkmark$ & Function as a Service (FaaS) \\
\hline Messaging Service & $\checkmark$ & $\checkmark$ & $\checkmark$ & Backend as a Service (BaaS) \\
\hline Mobile Application Service & $\checkmark$ & $\checkmark$ & $\checkmark$ & Backend as a Service (BaaS) \\
\hline
\end{tabular}

Each region in a zone is equipped with 4-tiers (Web, Application, Data, and Analytics. The proposed design enhanced the 3-zones design by MOELC by using Fog-Edge computing and virtualization technology. Each energy company in the distribution sector (public or private) will have its private block of service or function as service (FaaS) containing the 4 tiers (Figure 6). The description for each component of the design is provided as follows. 


\subsection{Block of Services}

\subsubsection{Web Tier/Presentation Tier}

The web tier handles communication between a web server and web browser with request reception through API [36]. The main advantage of this tier is its capability of handling all traffic while generating responses for incoming requests. In the proposed design, the web tier will respond to any API query made by the subscribers or SMs regarding network transactions. These requests will then be forwarded to the application tier.

\subsubsection{Application Tier}

The application tier is responsible for solving critical problems while achieving productivity advantages using resource sharing via specific application components based on business logic [37]. These components can help to enforce data rules, business algorithms, and regulations defined by the government to ensure that data structures are consistent within multiple or specific databases. Any request made by the user in the decentralized system of the proposed design will be resolved here. The application tier will perform actions based on the request of the users. If the request involves the transaction between a consumer and a producer, the application tier will execute actions.

\subsubsection{Data Tier (Database and Storage)}

The data-tier interacts with data stored in permanent storage or different database schemes in shared resources [37]. It also controls the stored data (hot or cold data type), manages the database system, and makes sure that data is independent of processing logic or application servers while enhancing overall performance and scalability. The data-tier in the proposed design will consist of information regarding the subscribers' transaction and energy consumption. This energy consumption data will be hosted in a secured and distributed environment privately, while subscribers will have the authority to share or manage their own personal data only.

\subsubsection{Analytics Tier}

The analytics tier is responsible for providing operational flexibility in the generation and distribution of the energy sector by mapping the value of data with analytics information such as power consumption forecasting [38]. Other functions include monitoring, troubleshooting, security analysis, long-term storage, and frequent ad-hoc analysis. In the proposed design, consumers' energy usage, related transactions, and contribution to the smart grid system will be monitored. Based on this information, the analytics tier will execute troubleshooting if any issue arises.

A few enhanced features like network and security subnets are included in the overall proposed design as seen in Figure 5. A network subnet is the division of a network into two or more networks to increase routing efficiency, improve network security, and enhance network management control [39]. For this purpose, high-speed data center switches, routers, and load balancers are used while using optical fiber links between servers and switches that have 10 Gbps and 25 Gbps network speeds. Moreover, next-generation firewalls with a recommended set of security requirements will be developed by security subnet in all communication interdependencies in the smart grid. These next-generation firewalls can prevent DDoS attacks by detecting it before its occurrence, using OpenFlow firewall algorithms [40]. This aspect disconnects the SG server from the network. However, in case of a strong DDoS attack, the security subnet will ensure that DDoS attacks cannot block all bandwidth, CPU power, and processing time of the smart grid (SG) servers by using a source tracking method. In the context of the present research, this method will detect the source of any attack made towards the proposed design and will be eliminated before it could harm the smart grid ecosystem.

Table 4 shows a summary of the technical comparison between the different computing technologies using the proposed design. 
Table 4. Summary of attributes of proposed FC-EC-SG over CC-SG and TC-SG.

\begin{tabular}{cccc}
\hline Attributes & TC-SG & CC-SG & $\begin{array}{c}\text { FC-EC-SG } \\
\text { (Proposed Design) }\end{array}$ \\
\hline Scalability & Low Scalability & High Scalability & High Scalability \\
Total Cost of Ownership & High & Medium & Low \\
Data Storage & Local & PaaS & FaaS \\
Dynamic Management & No & Yes & Yes \\
Real-Time Monitor & Medium & High & High \\
Data Traffic & High & Very High & Medium \\
Coverage-Distribution & Centralized & Decentralized & Decentralized \\
Mobility Support & No & Yes & Yes \\
\hline
\end{tabular}

\subsection{API Gateway}

API gateway is an essential tool for controlling and monitoring connected devices [41]. It provides easy transport for input/output data to SG-AMI systems from different regions, a more straightforward web-based configuration via any browser or any other type of application in a unified form, multiple communication protocols support and can connect machines to the virtual power plant and PLCs. The API gateway allows efficient communication between multiple devices in a network [42]. It can control, analyze, and monitor devices' requests while connecting heterogeneous smart meters devices. Besides, API gateway is a single-entry point for a selected block of services or microservices. It has access to support private cloud-based microservices for business processes such as user management, authentication, collaborative features, and much more [43]. Thus, this API gateway can act as a security door for a smart grid that would allow requests from authorized users and SMs to interact with it asynchronously and securely by sharing their private token with the desired application.

\subsection{External Backup Storage and Backup and Redundancy}

External backup storages are a basic safety precaution method that comes into play as soon as there is a system failure in the SG-AMI system to safeguard all crucial data in emergencies, such as natural disasters. It is an effective way of ensuring that the data related to customers subscribers and energy data such as generation, transmission, and distribution are saved in secure external storage away from the main infrastructure [44]. Furthermore, redundancy backup features are activated in an active-active mode or active-passive mode to ensure that the grid performance is not affected by external or internal faults and keeping the grid in a perfect working state [45]. The use of external storage and redundancy backup methods in the proposed SG-AMI can increase the system's reliability while reducing the risk of data loss in case of an emergency.

\section{Performance Evaluation}

To evaluate the performance of our proposed design across each computing scenario, i.e., CC-SG, FC-EC-SG, and TC-SG, a virtual laboratory environment was built using Microsoft Azure for both CC-SG and FC-EC-SG models. Three tiers architecture was used in Azure to achieve the design requirement (web, service plan application, and database servers) to represent our proposed design's one service block (Figure 6). The Azure and local environment's network components were optimized and reconfigured for each experiment to meet each scenario requirement. An improved system configuration and multi controls for data processing purposes have been deployed in a laboratory environment to read consumers' energy consumption, analyze the data, and evaluate proposed designs' performance. A sample of 200 households with smart meters installed was taken at a rate of energy consumption of around $6000 \mathrm{~W}$, representing a standard household use of electronic devices such as cooling systems, washing machine, TV, electric cooker, lighting, etc. The capacity of 15 power transmission stations $(20,000 \mathrm{~W})$, where Home Area Network (HAN) was considered as an area 
network with 1 Gbps and 10 Gbps capacity. In the grouped routers of our experiments, the following performance metrics were measured:

- Throughput: The number of data requests directed per second, measured in Kbps

- Latency: The average packet delay variation between the packet request and response, measured in milliseconds

- Time to response: The time is taken between data transmission and system response, measured in milliseconds.

The data traffic and data throughput for 200 houses were assumed to be on average of 5 devices per house (i.e., a total of 1000 devices). It was set for ten days, and two reading values were taken daily. Table 5 shows the lab configuration setting for each model, while Figure 7 shows our improved system interface used for reading and responding to lab test performance measurements.

Table 5. Lab configuration setting for all scenario models (CC, FC-EC and TC SG).

\begin{tabular}{cc}
\hline Component & Specifications \\
\hline CPU & Intel Xeon-2.1GHZ \\
RAM & $2 \times 32 \mathrm{~GB}$ \\
SSD & $1 \times 250 \mathrm{~GB}$ \\
OS & Linux and Microsoft Server \\
Database & SQL Server 2017 \\
NIC adapter & 10 and 25 Gb \\
Function Server & 3X Servers and 3 Tiers \\
Platform & Azure (for CC \& FC-EC) and local virtual servers (for TC) \\
Program Language & ASP.Net and C\# \\
\hline
\end{tabular}

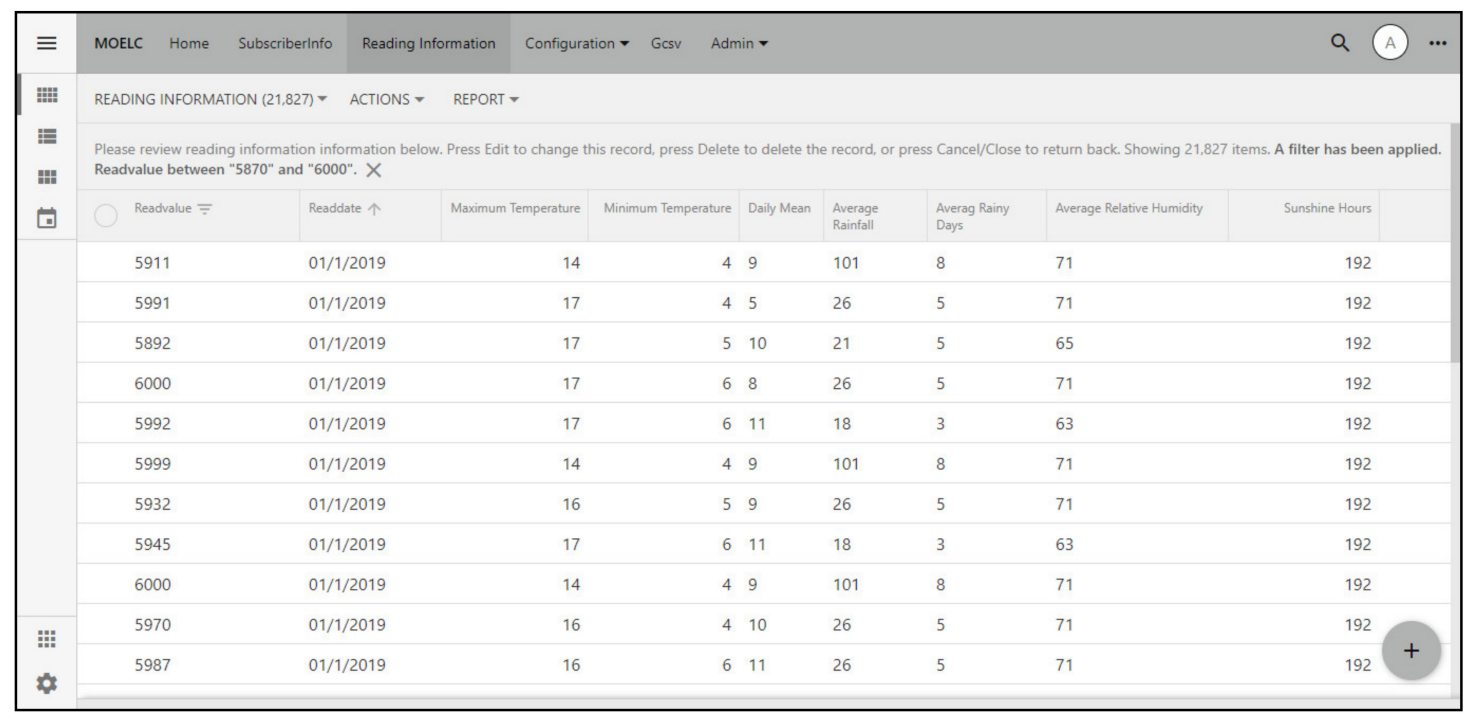

Figure 7. Improved system interface deployed in a laboratory environment for power consumption data.

Figure 8 shows the network traffic in CC-SG, FC-EC-SG, and TC-SG scenarios, while Figure 9 shows the average packet delay variation. Laboratory experiments have shown that when the demand for data traffic increases, FC-EC SG-AMI appears to be more efficient in reducing data rates that needed contact with the main services because it provides the required data to the consumer rather than forwarding the request to multi-services points in more than one location. This allows the reduction of network loads and data traffic in a general smart grid network. All approaches taken show a higher latency level or average packet delay variation as the volume of data sent increases over time. The proposed approach received a relatively low percentage compared to the rest of the approaches, where Network traffic load $(\mathrm{kb})$ show $20-45 \%$ of improvement, while latency $(\mathrm{ms})$ achieved around 
$35-65 \%$ improvement and time to response (ms) present 20-35\% of improvement compare to CC-SG and TC-SG, respectively.

$\bullet C C-S G \bullet F C-E C-S G \bullet T C-S G$

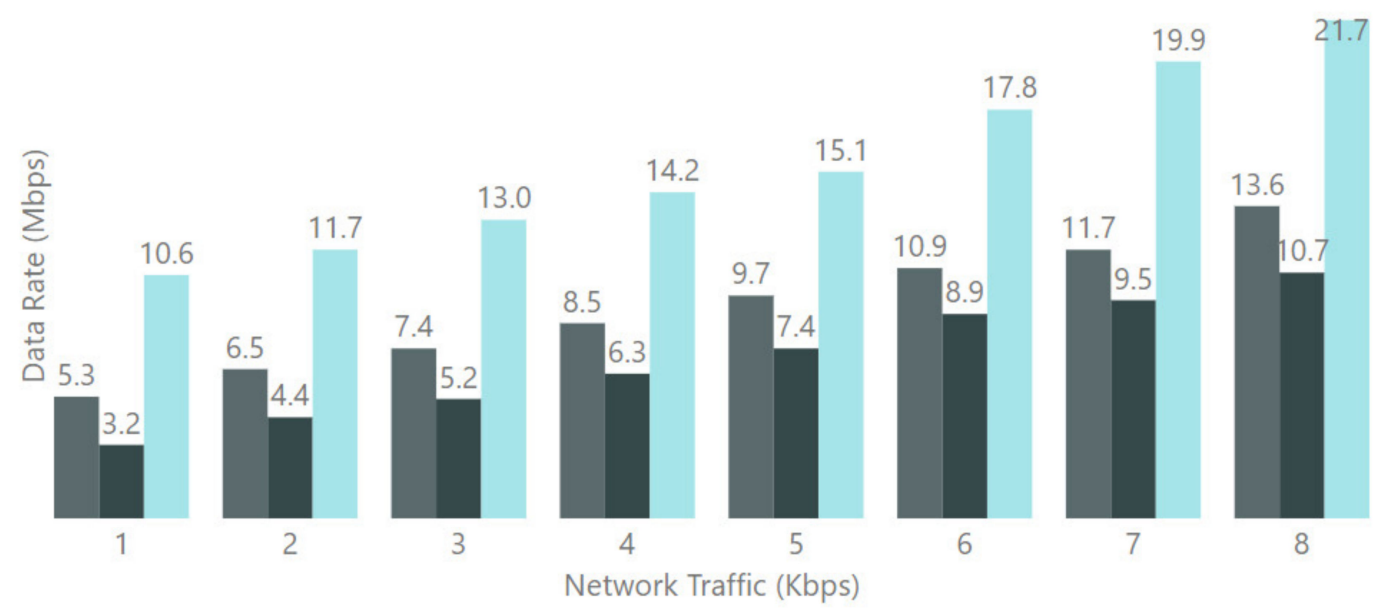

Figure 8. Network traffic in CC-SG, FC-EC-SG, and TC-SG.

$\bullet C C-S G \bullet F C-E C-S G \bullet T C-S G$

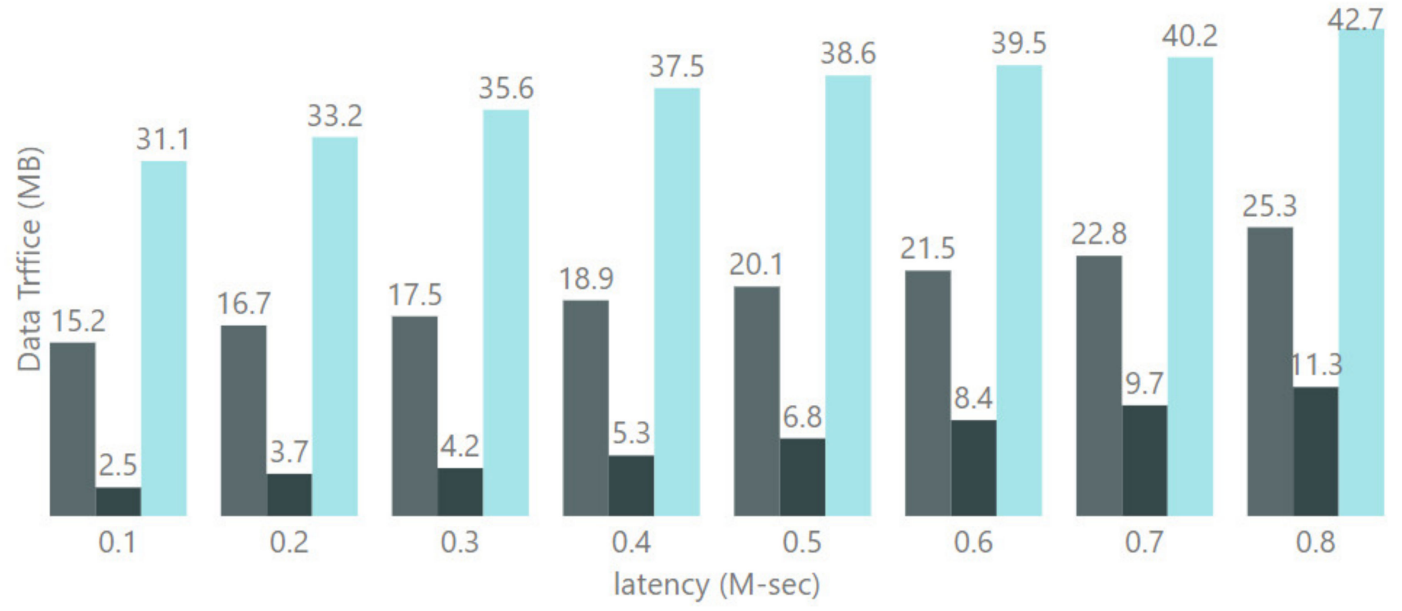

Figure 9. The average packet delay variation in CC-SG, FC-EC-SG, and TC-SG.

The response time compared to the increase in demand is also an important factor in determining the efficiency of any proposed design, where we examined the response time with a steady increase in the number of requests systematically, and the proposed approach gives the least response time as shown in Figure 10. 


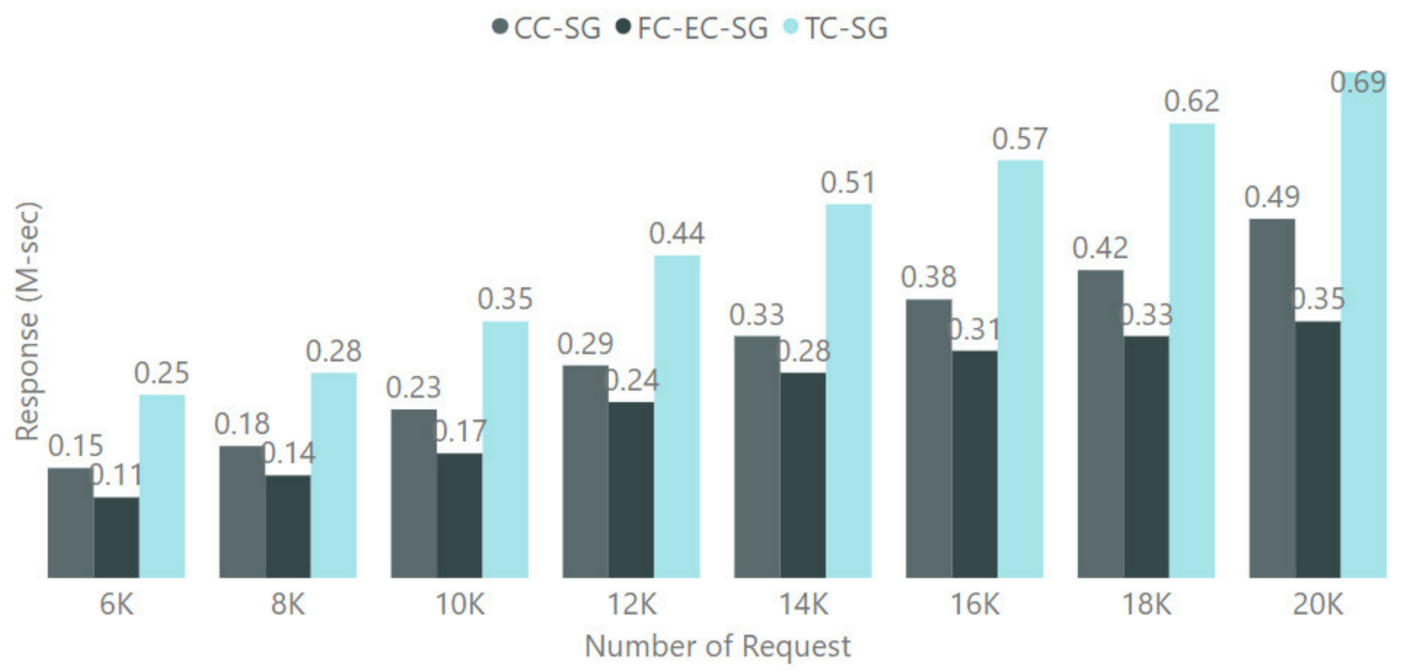

Figure 10. Time to response in CC-SG, FC-EC-SG, and TC-SG.

The proposed FC-EC SG-AMI architecture can also be evaluated by several metrics such as system availability, the total cost of ownership, power, and cooling consideration. The system availability, $A_{\text {system }}$ was derived as a ratio of Mean Time Between Failure (MTBF) and its Mean Time to Repair (MTTR). MTTR indicates the time required for repairing a system and bring it back to the normal state, while Mean Time between Failure (MTBF) is the predicted failure time during the operation of a system [46].

$$
\begin{gathered}
A_{\text {system }}=\frac{M T B F}{M T B F+M T T R} \\
M T T R=\frac{T_{\text {maintainance }}}{N_{\text {repairs }}} \\
M T B F=\frac{T_{\text {operational }}}{N_{\text {failures }}}=\frac{1 \times 10^{6}}{\lambda}
\end{gathered}
$$

where $T_{\text {maintainance }}$ is the total maintenance time, $T_{\text {operational }}$ is the total operational time, $N_{\text {repairs }}$ is the total number of repairs, $N_{\text {failures }}$ is the total number of failures and $\lambda$ is the mean number of failures per million hours. In ideal or standard situations, $A_{\text {system }}$ is expected to be close to $100 \%$ or $0.999 \%$ [47].

For ease of comparison, one Tier (e.g., Application Tier) in one region (e.g., region A) in a zone was considered for analysis, given by application group $\mathrm{A}\left(G_{A}\right)$. Six function servers $(X)$ are assumed in the $G_{A}$, where these servers' effectiveness was measured. Table 6 shows the MOELC physical ad FC-EC-SG virtual server specifications used in our assumption. As discussed at the beginning of the current section, the MOELC design is based on physical servers with a serial structure, while our design is based on virtual servers with a parallel structure. This means that six physical servers are needed for the MOELC design, while our proposed design will only need two to three servers to achieve the GA's requirements. Two cases are considered in more detailed for the proposed FC-EC-SG virtual server configuration:

- Case 1: Six Function Servers (X) in each application group, where each Server (S) can operate 2 functions

- Case 2: Six Function Servers $(X)$ in each application group, where each Server (S) can operate 3 functions. 
Table 6. MOELC physical ad FC-EC-SG virtual Servers Specifications.

\begin{tabular}{cc}
\hline Brand & Dell \\
\hline CPU & Intel Xeon-Gold Series \\
RAM & $6 \times 32$ GB \\
SSD & $4 \times 500 \mathrm{~GB}$ \\
\hline
\end{tabular}

Table 7 summarizes the server configurations for the MOELC physical server and Case 1 of FC-EC-SG virtual server designs.

Table 7. Comparison between virtual and physical server configuration for the $G_{A}$.

\begin{tabular}{|c|c|}
\hline MOELC Physical Server Configuration & FC-EC-SG Virtual Server Configuration (Case 1) \\
\hline S1- & S1 \\
\hline & $\mathrm{S} 1-$ \\
\hline S3-Public and Pri & S2-Public and Pri \\
\hline $\mathrm{S} 4$ & act \\
\hline S5-Distributed Ledger Technology (DLT) and Event & S3-Distributed Ledger Technology (DLT) and Event \\
\hline Management & Management \\
\hline S6-Transaction Routers and Ledger & S3-Transaction Routers and Ledger \\
\hline
\end{tabular}

In the server's serial structure, a failure of one server will affect other servers in the structure. Assuming a single server availability of $99.9 \%$, and $n$ is the number of serial devices or servers, the system availability is given by

$$
A_{\text {system, serial }}=A^{n}=0.999^{6}=99.4 \%
$$

However, with our proposed parallel server structure, the system availability remains in perfect condition, i.e., $A_{\text {system, parallel }}=99.9 \%$ for ideal or standard situations. Considering the total of 525,600 $\mathrm{min}$ in a year, this translates to downtime of only $52.6 \mathrm{~min} /$ year for virtual in comparison to 315.36 $\mathrm{min} /$ year for physical platforms. This indicates that our proposed design offers a better performance in system availability. Each physical server costs around USD7000, with a power requirement of $271 \mathrm{~W}$ and a cooling requirement of 1200 BTU. Table 8 summarizes the performance of MOELC proposed architecture and our proposed design. Server wise, the total cost of ownership, uninterruptible power supply (UPS), and cooling requirements for physical configuration is $50-67 \%$ higher than our proposed virtualized configuration.

Table 8. Summary of performance improvements.

\begin{tabular}{cccc}
\hline Aspects & MOELC Design & FC-EC-SG Design & $\begin{array}{c}\text { Improvements in } \\
\text { FC-EC-SG }\end{array}$ \\
\hline $\begin{array}{c}\text { System Availability } \\
\text { The total cost of } \\
\text { Ownership } \\
\text { Consideration }\end{array}$ & $\begin{array}{c}\text { Total (USD) } 42,000 \text { for } \\
\text { each Application Group }\end{array}$ & $\begin{array}{c}\text { Total (USD) } 21,000 \text { or } \\
14,000 \text { for each } \\
\text { Application Group }\end{array}$ & $50 \%$ to $67 \%$ \\
$\begin{array}{c}\text { Power and UPS } \\
\text { Considerations }\end{array}$ & Total (Watt) 1626 W & $\begin{array}{c}\text { Total (Watt) } 813 \text { W Or } \\
542 ~ W\end{array}$ & $50 \%$ to $67 \%$ \\
Cooling Consideration & Total (Watt) 7200 BTU & $\begin{array}{c}\text { Total (Watt) } 3600 \text { or } 2400 \\
\text { BTU }\end{array}$ & $50 \%$ to $67 \%$ \\
\hline
\end{tabular}

Moreover, the system capacity can be calculated based on the number of served requests (in request per second), in our case, the number of SMs or the number of subscribers' requests that are served in the block of services. This will mainly be based on server hardware specifications and available resources such as CPU type and the number of the processor core, RAM capacity, and storage disk read 
and write speeds. Moreover, the amount of data sent per request, and the number of requests should be per day, and an hourly basis for each object such as SM will also affect the overall system capacity. This information is dynamic as it depends on the smart meter usage specifications and the amount of mobile data need per transaction. Therefore, it must be calculated for each company independently to determine the required resources available for each block of service. Table 9 shows the estimated need for each server's required resources to serve 25,000 standard three-phase smart meters [48].

Table 9. The estimations of resources required that need to operate 25,000 smart meters.

\begin{tabular}{ccccc}
\hline Server & QTY & Core Per CPU & RAM & Storage \\
\hline Web Server & 2 & 16-32 C per server & 128-256 GB & 1 TB SSD 12GB read/write speed \\
Application Server & 2 & 16-32 C per server & 128-256 GB & 1 TB SSD 12GB read/write speed \\
Database Server & 2 & 32-64 C per server & 256-512 GB & 2 TB SSD 12GB read/write speed/per year \\
\hline
\end{tabular}

The expected advantages of Serverless SG-AMI proposed design in smart grid architecture are summarized as follows:

- $\quad$ Reduced Operation Cost: Serverless SG-AMI offer a unified structure that will reduce the total costs of ownership required to build an independent infrastructure for each company operating in this field. Instead, these companies will pay as grow by using MOELC function as a service (FaaS) model.

- Elasticity Through Independent Environment: Serverless SG-AMI design offers the separation of physical hardware and software and function layer from that of the virtual layer, enabling users to run non-compliant or, in some cases, obsolete operating systems on newer or alternate hardware. These technologies allow system upgrades and non-disruptive testing, where different software versions can run in parallel with physical hardware. Moreover, virtualization provides flexibility in server allocation, hence allowing users to choose the virtual server to execute a physical server application. On the other hand, the use of hardware-based servers in the proposed design would somehow reduce the flexibility because each server would require manual installation of an operating system. It would restrict the proposed design from running a non-compliant operating system.

- Performance Tuning: Serverless SG-AMI design significantly improves system software performance by running multiple platforms across a distributed architecture. Moreover, cross-platform systems can also be monitored, altered, or changed towards certain needs, reducing the risk of performance degradation. The performance of data centers of the SG-AMI can be optimized using the proposed architecture, as it contributes to abnormal delay variations that affect overall system efficiency.

- Simplified Resources Management: The proposed architecture provides efficient handling and monitoring of different types of SMs and many computing and networking resources. It makes resource management easier because the virtual servers have flexible resource expansion capability. SG-AMI possess the potential to increase computing resources' efficiency by applying dynamic resource calling, micro-service sharing, and FaaS model.

- Flexible Scalability: With SG-AMI, several components such as smart meters, sensors, network servers, and other resources can be operated, tested, and scaled up when needed. This reduces the hardware deployment cost need for system testing. Besides that, it utilizes FaaS services and allows communication with external applications through API Gateway. This is incredibly useful in the proposed design as it offers flexible upscaling depending on the future needs as the system grows. In other words, it assures that no excess cost is being wasted.

- Marketing Adaptation: The proposed SG-AMI can also handle the changes associated with future consumer demands, energy profile of consumers, and environmental concerns by offering support to potential services and artificial intelligence (AI) analytic applications through a flexible FaaS 
model. The combination of blockchain and AI techniques can observe and identify consumers' energy patterns and enable a value-added and tailored provision of energy products.

\section{Conclusions}

The paper proposed a comprehensive Serverless Fog-Edge Computing for SG-AMI architecture to improve the SG design provided by Iraqi MOELC. A Serverless Fog-Edge Computing with integrated virtualization technology-based architecture promises several benefits: reduced traffic complexities, improved scalability, and reduced TCO. This combination provides an efficient computing architecture while maintaining the data processing in the distributed network and decentralized services. The proposed architecture was also compared with traditional computing as proposed by MOELC and the pure cloud computing architecture, using different metrics such as network traffic load, latency, and time to respond. It was observed that the proposed FC-EC-SG reduces the total cost of ownership, power, and cooling consumptions while increasing the overall performance. However, Serverless architecture has some limitations that need more attention from researchers such as data security and privacy, dynamic business logic design, cost-effectiveness in long-running processes, and testing and debugging of new functionality. Furthermore, with its flexibility, the design is adaptable to blockchain services, which have gained increasing attention in modern technology to enable transparent transactive energy. Decentralizing the smart grid with blockchain service would require the system node's approval for any blockchain structure changes. This might create more advantages but also security vulnerabilities if it is largely adopted in the energy sector with our current design. We are looking at this perspective for our next research work.

Author Contributions: A.A. conceived the presented idea, developed the theory and performed the computations. A.H.M. contributed in the investigation and R.N. in the conceptualization. N.F.A. and A.A.-S. verified the analytical methods and supervised the findings of this work. All authors discussed the results and contributed to the final manuscript. All authors have read and agreed to the published version of the manuscript.

Funding: This research received funding from Malaysian Ministry of Higher Education grant FRGS/1/2018/ICT03/ $\mathrm{UKM} / 02 / 3$.

Acknowledgments: A. Albayati would like to thank the Iraqi Ministry of Higher Education and the Ministry of Electricity for their support on this research.

Conflicts of Interest: The authors declare no conflict of interest.

\section{References}

1. NIST. Transactive Energy: An Overview. 2019. Available online: https://www.nist.gov/engineeringlaboratory/smart-grid/transactive-energy-overview (accessed on 5 November 2019).

2. Tuttokmagi, O.; Kaygusuz, A. Smart Grids and Industry 4.0. In Proceedings of the 2018 International Conference on Artificial Intelligence and Data Processing (IDAP), Malatya, Turkey, 28-30 September 2018; pp. 1-6.

3. Ghosal, A.; Conti, M. Key Management Systems for Smart Grid Advanced Metering Infrastructure: A Survey. IEEE Commun. Surv. Tutor. 2019, 21, 2831-2848. [CrossRef]

4. Zafar, R.; Mahmood, A.; Razzaq, S.; Ali, W.; Naeem, U.; Shehzad, K. Prosumer based energy management and sharing in smart grid. Renew. Sustain. Energy Rev. 2018, 82, 1675-1684. [CrossRef]

5. Saleem, Y.; Crespi, N.; Rehmani, M.H.; Copeland, R. Internet of Things-Aided Smart Grid: Technologies, Architectures, Applications, Prototypes, and Future Research Directions. IEEE Access 2019, 7, 62962-63003. [CrossRef]

6. Magee, T.; Prettitore, J. Advanced Metering Infrastructure Business Plan. Con Edison AMI Business Plan. 2015. Available online: http://nyssmartgrid.com/wp-content/uploads/Con-Ed-AMI-Business-Plan.pdf (accessed on 5 November 2019).

7. Chan, J.; Ip, R.; Cheng, K.; Chan, K.S. Advanced Metering Infrastructure Deployment and Challenges. In Proceedings of the 2019 IEEE PES GTD Grand International Conference and Exposition Asia (GTD Asia), Bangkok, Thailand, 20-23 March 2019; pp. 435-439. 
8. Rajakumar, P.; Puviyarasi, R.; Singh, S. Power Management and Advanced Metering Infrastructure Using Wireless Network in Remote Areas. In Proceedings of the 2018 International Conference on Power Energy, Control and Transmission Systems (ICPECTS), Chennai, India, 22-23 February 2018; pp. 210-213.

9. Beard, C. Smart Metering for Dummies. John Wiley and Sons, Ltd.: Chichester, UK, 2010; Available online: https://www.smartme.co.uk/documents/smart_metering_for_dummies.pdf (accessed on 5 November 2019).

10. Malik, S.A.; Gondal, T.M.; Ahmad, S.; Adil, M.; Qureshi, R. Towards Optimization Approaches in Smart Grid a Review. In Proceedings of the 2019 2nd International Conference on Computing, Mathematics and Engineering Technologies (iCoMET), Sukkur, Pakistan, 30-31 January 2019; pp. 1-5.

11. Al-Khatteb, L.; Istenpanian, H. Turn a Light on: Electricity Sector Reform in Iraq. Brookings Institution. 2015. Available online: https://www.researchgate.net/publication/273949491_Turn_a_Light_on_Electricity_Sector_ Reform_in_Iraq (accessed on 5 November 2019).

12. MIT Energy Hack. This challenge for the 2018 MIT Energy Hackathon was developed by Robert Trinnear of Candor Energy. In MIT Energy Hack. 2018. Available online: https://www.mitenergyhack.org/s/CandorProblem-Statement-for-MIT-Hackathon-latest-HS-edits-final.docx (accessed on 6 November 2019).

13. Radoglou-Grammatikis, P.I.; Sarigiannidis, P.G. Securing the Smart Grid: A Comprehensive Compilation of Intrusion Detection and Prevention Systems. IEEE Access 2019, 7, 46595-46620. [CrossRef]

14. Yousefpour, A.; Fung, C.; Nguyen, T.; Kadiyala, K.; Jalali, F.; Niakanlahiji, A.; Kong, J.; Jue, J.P. All one needs to know about fog computing and related edge computing paradigms: A complete survey. J. Syst. Arch. 2019, 98, 289-330. [CrossRef]

15. Dileep, G. A survey on smart grid technologies and applications. Renew. Energy 2020, 146, $2589-2625$. [CrossRef]

16. Zhang, S.; Luo, X.; Litvinov, E. Serverless computing for cloud-based power grid emergency generation dispatch. Int. J. Electr. Power Energy Syst. 2020, 124, 106366. [CrossRef]

17. Jacobs, S. Function as a Service. 2018. Available online: https://blog.oio.de/2018/02/14/function-as-a-service/ (accessed on 5 August 2020).

18. Hussain, M.; Alam, M.; Beg, M. Fog Computing in IoT Aided Smart Grid Transition-Requirements, Prospects, Status Quos and Challenges. arXiv, 2019; arXiv:1802.01818.

19. Zahoor, S.; Javaid, N.; Khan, A.; Ruqia, B.; Muhammad, F.J.; Zahid, M. A Cloud-Fog-Based Smart Grid Model for Efficient Resource Utilization. In Proceedings of the 2018 14th International Wireless Communications \& Mobile Computing Conference (IWCMC), Limassol, Cyprus, 25-29 June 2018; pp. 1154-1160.

20. Ullah, R.; Javaid, N.; Iqbal, Z.; Ahmad, I.; Jan, A.; Jadoon, Y. CRRP Analysis of Cloud Computing in Smart Grid. Advances in Intelligent Systems and Computing. In Complex, Intelligent, and Software Intensive Systems. CISIS 2018. Advances in Intelligent Systems and Computing; Springer: Cham, Switzerland, 2018; Volume 772, pp. 64-74. Available online: https://link.springer.com/chapter/10.1007/978-3-319-93659-8_6 (accessed on 6 November 2019).

21. De Sousa, J.V.; Reche, E.A.; Coury, D.V.; Fernandes, R.A. Cloud computing in the smart grid context: An application to aid fault location in distribution systems concerning the multiple estimation problem. IET Gener. Transm. Distrib. 2019, 13, 4222-4232. [CrossRef]

22. Fatima, I.; Javaid, N.; Iqbal, M.N.; Shafi, I.; Anjum, A.; Memon, U.U. Integration of Cloud and Fog based Environment for Effective Resource Distribution in Smart Buildings. In Proceedings of the 2018 14th International Wireless Communications \& Mobile Computing Conference (IWCMC), Limassol, Cyprus, 25-29 June 2018; pp. 60-64.

23. Pau, M.; Patti, E.; Barbierato, L.; Estebsari, A.; Pons, E.; Ponci, F.; Monti, A. A cloud-based smart metering infrastructure for distribution grid services and automation. Sustain. Energy Grids Netw. 2018, 15, 14-25. [CrossRef]

24. Ghorbanian, M.; Dolatabadi, S.H.; Masjedi, M.; Siano, P. Communication in Smart Grids: A Comprehensive Review on the Existing and Future Communication and Information Infrastructures. IEEE Syst. J. 2019, 13, 4001-4014. [CrossRef]

25. Kumari, A.; Tanwar, S.; Tyagi, S.; Kumar, N.; Obaidat, M.S.; Rodrigues, J.J.P.C. Fog Computing for Smart Grid Systems in the 5G Environment: Challenges and Solutions. IEEE Wirel. Commun. 2019, 26, 47-53. [CrossRef] 
26. Hussain, M.M.; Alam, M.; Beg, M.S. Feasibility of Fog Computing in Smart Grid Architectures. In Proceedings of the 2nd International Conference on Communication, Computing and Networking; Lecture Notes in Networks and Systems; Springer: Singapore, 2018; Volume 46, pp. 999-1010. Available online: https://link.springer. com/chapter/10.1007/978-981-13-1217-5_98 (accessed on 6 November 2019).

27. Aazam, M.; Zeadally, S.; Harras, K.A. Deploying Fog Computing in Industrial Internet of Things and Industry 4.0. IEEE Trans. Ind. Inform. 2018, 14, 4674-4682. [CrossRef]

28. Liu, Y.; Yang, C.; Jiang, L.; Xie, S.; Zhang, Y. Intelligent Edge Computing for IoT-Based Energy Management in Smart Cities. IEEE Netw. 2019, 33, 111-117. [CrossRef]

29. Chen, S.; Wen, H.; Wu, J.; Lei, W.; Hou, W.; Liu, W.; Xu, A.; Jiang, Y. Internet of Things Based Smart Grids Supported by Intelligent Edge Computing. IEEE Access 2019, 7, 74089-74102. [CrossRef]

30. Attarha, S.; Narayan, A.; Hassan, B.H.; Krüger, C.; Castro, F.; Babazadeh, D.; Lehnhoff, S. Virtualization Management Concept for Flexible and Fault-Tolerant Smart Grid Service Provision. Energies 2020, 13, 2196. [CrossRef]

31. Chen, L.; Liu, J.; Ha, W. Cloud Service Risk in the Smart Grid. In Proceedings of the 2018 14th International Conference on Computational Intelligence and Security (CIS), Hangzhou, China, 16-19 November 2018; pp. 242-244.

32. Worighi, I.; Maach, A.; van Mierlo, J.; Hegazy, O. Towards a Realistic Design of Hybrid Micro-Grid Systems Based on Double Auction Markets. In Advances in Intelligent Systems and Computing; Springer: Cham, Switzerland, 2019; pp. 81-96. Available online: https://ink.springer.com/chapter/10.1007/978-3-030-12065-8_9 (accessed on 6 November 2019).

33. Shaileshwari, M.; Prasad, K.N.; Paventhan, A. Software Defined Networking for Smart Grid Communications and Security Challenges; ISGW 2017: Compendium of Technical Papers; Springer: Berlin/Heidelberg, Germany, 2018; pp. 103-112. Available online: https://link.springer.com/chapter/10.1007/978-981-10-8249-8_9 (accessed on 6 November 2019).

34. Aderibole, A.; Aljarwan, A.; Rehman, M.; Zeineldin, H.H.; Mezher, T.; Salah, K.; Damiani, E.; Svetinovic, D. Blockchain Technology for Smart Grids: Decentralized NIST Conceptual Model. IEEE Access 2020, 8, 43177-43190. [CrossRef]

35. Iraqi Ministry of Electricity (MOELC). Technical Specification of Head End System (HES) for Smart Metering System. 2019. Available online: https://moelc.gov.iq/ (accessed on 10 June 2019).

36. Wang, Q.; Chen, H.; Zhang, S.; Hu, L.; Palanisamy, B. Integrating Concurrency Control in n-Tier Application Scaling Management in the Cloud. IEEE Trans. Parallel Distrib. Syst. 2018, 30, 855-869. [CrossRef]

37. Microsoft. Using a Three-Tier Architecture Model-Win32 apps. 2019. Available online: https: //docs.microsoft.com/en-us/windows/win32/cossdk/using-a-three-tier-architecture-model (accessed on 6 November 2019).

38. Sumologic, “Analytics Tiers”, Sumo Logic. 2019. Available online: https://help.sumologic.com/Manage/ Partitions/Analytics_Tiers (accessed on 6 November 2019).

39. Udeagha, C.; Clarke, A.; Francis, S.; Perry, H.; Elliot, K.; Afflick, Z. Network Design \& Improvement, Using Riverbed Academic Edition, Version 17.5 in University of Technology, Jamaica. In Proceedings of the SoutheastCon 2018, St. Petersburg, FL, USA, 19-22 April 2018; pp. 1-8. [CrossRef]

40. Diovu, R.C.; Agee, J.T. A cloud-based openflow firewall for mitigation against DDoS attacks in smart grid AMI networks. In Proceedings of the 2017 IEEE PES PowerAfrica, Accra, Ghana, 27-30 June 2017; pp. $28-33$.

41. Kim, J.; Park, B.-S.; Park, Y.-U. Flooding Message Mitigation of Wireless Content Centric Networking for Last-Mile Smart-Grid. Appl. Sci. 2019, 9, 3978. [CrossRef]

42. Nugur, A.; Pipattanasomporn, M.; Kuzlu, M.; Rahman, S. Design and Development of an IoT Gateway for Smart Building Applications. IEEE Internet Things J. 2019, 6, 9020-9029. [CrossRef]

43. Zhao, J.T.; Jing, S.Y.; Jiang, L.Z. Management of API Gateway Based on Micro-Service Architecture. J. Phys. Conf. Ser. 2018, 1087, 032032. [CrossRef]

44. Saini, S.; Beniwal, R.K.; Kumar, R.; Paul, R.; Saini, S. Modelling for Improved Cyber Security in Smart Distribution System. Int. J. Future Revolut. Comput. Sci. Commun. Eng. 2018, 4, 56-59.

45. Luo, Y.; Luo, Y.; Ye, X.; Lu, J.; Li, S. Reliability-Based and QoS-Aware Service Redundancy Backup Method in IoT-Based Smart Grid; Lecture Notes in Computer Science; Springer: Cham, Switzerland, 2019; pp. 588-598. Available online: https://link.springer.com/chapter/10.1007/978-3-030-24268-8_54 (accessed on 6 November 2019). 
46. Foskett, S. Defining Failure: What Is MTTR, MTTF, and MTBF? 2019. Available online: https://blog.fosketts. net/2011/07/06/defining-failure-mttr-mttf-mtbf/ (accessed on 7 November 2019).

47. ABB. Network Manager Virtualizaiton, ABB. 2019. Available online: https://new.abb.com/networkmanagement/ (accessed on 1 November 2019).

48. LUNA. Three Phase Smart Meters. 2020. Available online: https://www.lunatr.com/en/uc-phase-counters/ (accessed on 5 August 2020).

Publisher's Note: MDPI stays neutral with regard to jurisdictional claims in published maps and institutional affiliations.

(C) 2020 by the authors. Licensee MDPI, Basel, Switzerland. This article is an open access article distributed under the terms and conditions of the Creative Commons Attribution (CC BY) license (http://creativecommons.org/licenses/by/4.0/). 